\title{
MITRAL ANÜLÜS KALSIFIKASYONUNUN ELEKTROKARDIYOGRAM PARAMETRELERI ÜZERINDE ETKILERI
}

\author{
THE EFFECTS OF MITRAL ANNULAR CALCIFICATION ON \\ ELECTROCARDIOGRAM PARAMETERS
}

\author{
Mevlüt Serdar KUYUMCU1 ${ }^{1}$ Çağrı YAYLA² \\ ${ }^{1}$ Isparta Süleyman Demirel Üniversitesi Kardiyoloji Kliniği \\ 2 Türkiye Yüksek İhtisas Eğitim Araştırma Hastanesi Kardiyoloji Klinioği
}

Cite this article as: Kuyumcu MS, Yayla Ç. The effects of mitral annular calcification on electrocardiogram parameters. Med J SDU 2019; 26(3): 274-279.

\section{Öz}

\section{Amaç}

Mitral anüler kalsifikasyon (MAK) mortalite indikatörü olan azalmış kalp hızı değişkenliği, bozulmuş P dalgası dispersiyonu ve atriyal elektromekanik gecikme ile ilişkili olduğu saptanmıştır. MAK'ın potansiyel aritmojenik etkileri olabileceğini göz önüne alarak çalışmamızda MAK'ın kalbin elektrofizyolojisi üzerine etkilerini klasik EKG parametrelerine ek olarak $f(Q R S-T)$ açısı ve Tp-e/QT gibi yeni aritmojenik idikatörleri kullanarak araştırmayı amaçladık.

\section{Gereç ve Yöntem}

Toplam 200 ardışık hasta [n=100 MAK (+) ve $n=100$ MAK (-)] çalışmaya dahil edildi. Toplanılan tüm veriler ve elektrokardiyogram parametreleri gruplar arasında karşılaştırıldı.

\section{Bulgular}

P Dalgası MAK (+) grubunda, kontrol grubuna göre anlamlı şekilde uzun izlenmiştir $(p<0.001)$. Düzeltilmiş QT intervali MAK (+) grubunda, kontrol grubuna göre anlamlı olarak uzun izlenmiştir $(p<0.001)$. Tp-e intervali MAK (+) grubunda, kontrol grubuna göre anlamlı olarak uzun izlenmiştir $(p<0.001)$. Tp-e/ QT intervali ve Tp-e/ düzeltilmiş QT intervali oranı MAK (+) grubunda, kontrol grubuna göre anlamlı olarak uzun izlenmiştir ( $p<0.001)$. Frontal QRS-T açıSı MAK (+) grubunda anlamlı olarak fazla izlenmiştir $(p<0.001)$.

\section{Sonuç}

Çalışmamızda MAK'ın EKG üzerindeki etkileri değerlendirilmiştir ve literatürde ilk kez MAK'ın kalbin repolarizasyon parametreleri üzerinde negatif etkileri olduğu saptanmıştır.

Anahtar Kelimeler: Mitral anülüler kalsifikasyon, EKG, QRS-T açısı

\section{Abstract}

\section{Objective}

Mitral annular calcification (MAK) has been found to be associated with mortality indicators such as reduced heart rate variability, impaired $\mathrm{P}$ wave dispersion and atrial electromechanical delay. Taking into consideration that MAK may have potential arrhythmogenic effects, we aimed to investigate the effects of MAK on cardiac electrophysiology using classical ECG parameters in addition to new arrhythmogenic determinants such as f(QRS-T) angle and Tp-e/QT.

\section{Material and Methods}

Total 200 consecutive patients $[n=100 \operatorname{MAK}(+)$ ve $\mathrm{n}=100 \operatorname{MAK}(-)]$ were included study. All collected

İletişim kurulacak yazar/Corresponding author: kuyumcuserdar@hotmail.com

Müracaat tarihi/Application Date: 26.07.2018 - Kabul tarihi/Accepted Date: 11.09.2018

Available online at http://dergipark.gov.tr/sdutfd

Makaleye http://dergipark.gov.tr/sdutfd web sayfasından ulaşılabilir. 
data and ECG parametreds were compared between groups.

\section{Results}

$P$ wave was significantly longer in the MAK (+) group than the control group $(p<0.001)$. Corrected QT interval was significantly longer in the MAK (+) group than the control group $(p<0.001)$. Tp-e interval was significantly longer in the MAK (+) group than the control group $(p<0.001)$. Tp-e / QT interval and Tp-e / corrected QT interval ratio were significantly longer in the MAK (+) group than the control group $(p<0.001)$. The frontal QRS-T angle was significantly higher in the MAK (+) group $(p<0.001)$.

\section{Discussion}

We assessed the effects of MAK on ECG in our study and it has been found that for the first time in the literature, MAK has negative effects on cardiac repolarization parameters.

Keywords: Mitral annular calcification, ECG, QRS-T angle

\section{Giriş}

Mitral anüler kalsifikasyon (MAK), mitral kapak anülüsünün kalsifikasyonu ve fibrozisi ile seyreden mitral kapağın kronik ve dejeneratif bir hastalığıdır (1). MAK'ın karotis arter hastalığı ve koroner arter hastalığı gibi aterosklerotik hastalıklarla bağlantılı olduğu gösterilmiştir $(1,2)$. MAK, total mortalite ve kardiyovasküler mortalitede artış ile ilişkilidir (3). MAK'ın aterosklerotik süreç için bir indikatör olduğu düşünülmektedir (4). Ateroskleroz ve MAK; obezite, yaş, hipertansiyon, hiperlipidemi ve diyabet gibi benzer risk faktörlerine sahiptir (5). Ayrıca inflamasyon, oksidatif stres ve lipit metabolizmasındaki bozukluklar iki hastalığın patogenezinde önemli rol oynamaktadır (6).

Gecikmiş ventriküler repolarizasyon, ventriküler aritmiler ile ilişkilidir (7). QT intervali, QT dispersiyonu ve T-dalgası ölçümleri kullanılarak EKG'de ventriküler repolarizasyon belirlenebilir. Son çalışmalar Tp-e araIığının, T dalgasının tepe ve sonu arasındaki aralığın, repolarizasyonun toplam dispersiyon indeksi olarak belirtildiğini ortaya koymuştur (8). Uzatılmış Tp-e araIığı, ventriküler aritmileri ve mortaliteyi; tek başına QT aralığına göre daha iyi öngörebilir (9). Bu nedenle, Tp-e/QT oranının ventriküler depolarizasyonun daha iyi bir göstergesi olduğu ileri sürülmüştür (10).

Son yıllarda ventriküler depolarizasyon (QRS ekseni) ve repolarizasyon ( $T$ ekseni) yönleri arasındaki açı olarak tanımlanan Frontal düzlem QRS-T [f(QRS-T)] açısı (Şekil 1), ventriküler repolarizasyon heterojenliğinin yeni bir belirteci olarak tanımlanmıştır (11). Bir çok çalışmada farklı popülasyonlarda f(QRS-T) açısının prognostik değeri gösterilmiştir $(11,12)$. Bu çalışmalara ek olarak, yeni bir çalışmada, geniş bir f(QRS - T) açının (>90 ${ }^{\circ}$ ), akut miyokard enfarktüsü geçirdikten sonra sol ventrikül sistolik disfonksiyonu olan hastalarda uzun süreli mortalitenin iyi bir göstergesi olduğu gösterilmiştir (13).

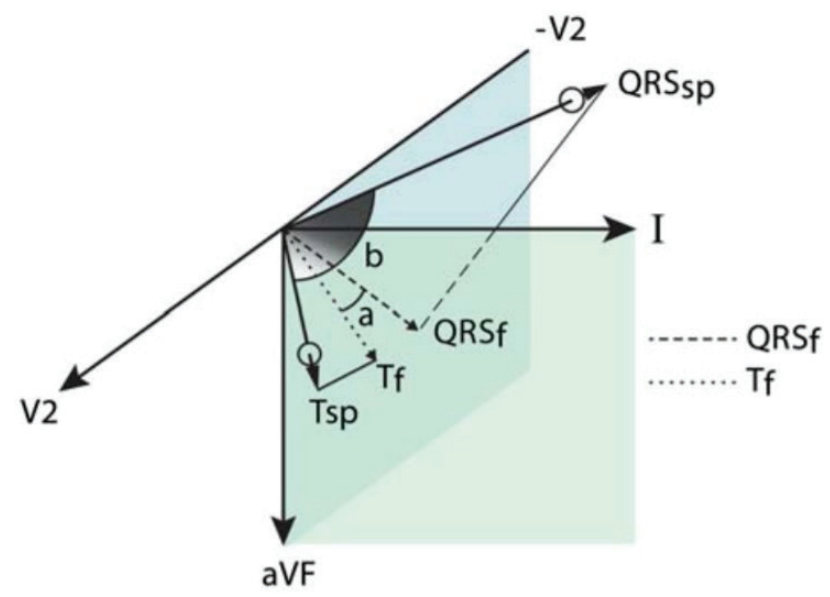

Şekil 1: Şekil de spasyal QRS vektörü QRSsp, spasyal T vektörü Tsp, frontal QRS vektörü QRSf, frontal QRS vektörü QRSf olarak gösterilmiştir. "Frontal QRS-T açısı" "a", "Spasyal QRS-T açısı" "b” olarak gösterilmiştir. Biz çalışmamızda Frontal QRS-T açısını kullandık.

MAK'ın daha önce; mortalite indikatörü olan azalmış kalp hızı değişkenliği, bozulmuş $P$ dalgası dispersiyonu ve atriyal elektromekanik gecikme ile ilişkili olduğu saptanmıştır (14). Bizde çalışmamızda MAK'ın kalbin elektrofizyolojisi üzerine etkilerini klasik EKG parametrelerine ek olarak f(QRS-T) açısı ve Tp-e/QT gibi yeni aritmojenik idikatörleri kullanarak araştırmayı planladık.

\section{Gereç ve Yöntem}

Türkiye Yüksek Ihtisas Hastanesi otomasyon sistemini kullanarak, kardiyoloji polikliniğine başvuran ve MAK saptanan hastaları saptayarak retrospektif kesitsel bir çalışma planlamıştır. Aralık 2016 ve Ekim 2017 arasında hastanemize başvuran toplam 200 ardışık hasta $[\mathrm{n}=100$ MAK (+) ve n=100 MAK (-)] çalışmaya dahil edildi. Ciddi kalp kapak hastalığı, akut romatiz- 
mal ateş öyküsü, prostetik kapağı, dekompanse kalp yetmezliği, malignitesi, böbrek veya karaciğer disfonksiyonu, akut veya kronik inflamatuar hastalığı, hematolojik hastalığı ve kronik obstrüktif akciğer hastalığı olan hastalar çalışma dışı bırakıldı. Temel demografik ve klinik özellikler otomasyon sisteminden alındı. $\mathrm{Hi}-$ pertansiyon en az iki ölçümle sistolik kan basıncının $\geq 140 \mathrm{mmHg}$ ve/veya diyastolik kan basıncının $\geq 90$ $\mathrm{mmHg}$ saptanması veya aktif olarak antihipertansif ilaç kullanımı olarak tanımlandı. Diabetes mellitus, açlık plazma glukoz düzeyi $6.9 \mathrm{mmol} / /$ üzerinde veya herhangi bir ölçümde $11.1 \mathrm{mmol} / /$ üzerinde glikoz seviyesi saptanması veya antidiyabetik ilaç kullanımı olarak tanımladı. Çalışma Helsinki Deklarasyonu'nda belirtilen ilkelere uygundur ve yerel kurumsal etik komitesi tarafından onaylanmıştır.

Ekokardiyografik değerlendirme 3.5 MHztransducer ve VIVID 7 Dimension Cardiovascular Ultrasound System (Vingmed-General Electric, Horten, Norway) cihazı kullanılarak yapılmıştır. İşlem sol lateral dekübit pozisyon kullanılarak yapılmıştır. Parasternal uzun ve kısa akslar ve apikal akslar standart görüntüleme pencereleri olarak kullanılmıştır. Sol ventriküler ejeksiyon fraksiyonu modifiye Simpson Metodu kullanılarak yapılmıştır. Tüm ekokardiyografik görüntüler deneyimli bir kardiyolog tarafından analiz edilmiştir. Mitral anülüs kalsifikasyonu, parasternal uzun veya kısa eksende, apikal dört veya iki boşluk görüntüleri açısında atriyoventriküler oluk ile mitral kapak ön veya arka yaprakçığın birleştiği yerde lokalize olan oldukça yansıtıcı özellikleri olan yoğun ekokardiyografik yapı olarak tanımlanmıştır (15).

Çalışmamızda, 12-derivasyonlu EKG, supin pozisyonda $50 \mathrm{~mm} / \mathrm{s}^{\prime}$ lik bir kağıt hızında kaydedildi. Tüm EKG'ler tarayıcıda tarandı ve hata ölçümlerini azaltmak için kişisel bir bilgisayara aktarıldı ve Adobe Photoshop yazılımı ile \%400 büyütme için kullanıldı. EKG'lerinde $U$ dalgası olan kişiler çalışmadan çıkarıldı. Her bir derivasyon için ortalama üç değer değeri hesaplandı. QT aralığı QRS kompleksinin başlangıcından T dalgasının sonuna kadar ölçülmüş ve Bazett formülü kullanılarak kalp (cQT $=\mathrm{QT} \sqrt{ }(\mathrm{R}-\mathrm{R}$ interval) atım hızı için düzeltilmiştir. Tp-e aralığı $T$ dalgasının tepe noktasından $T$ dalgasının sonuna kadar olan aralık olarak tanımlanmıştır. Tp-e aralığı prekordiyal derivasyonlardan ölçülmüştür (16). Frontal QRS ve T-dalgası açıları Adobe Photoshop yazılımı ile\% 400 büyütme yardımı ile bilgisayar programı kullanılarak ölçülmüştür. Frontal QRS açı hesaplaması, bu eksenlerden, frontal düzlem QRS ekseni ve frontal düzlem T ekseni arasındaki mutlak fark olarak hesaplanmıştır. Açı $180^{\circ}$ 'yi geçerse, $360^{\circ}$ ' den çıkarılarak hesaplanmıştır $(11,12,17)$.
Hastane rutini olarak hastalardan 12 saatlik açlıktan sonra biyokimyasal incelemeler ve tam kan sayımı için venöz kan örnekleri alındı. Tam kan sayımı için kan örnekleri EDTA içeren tüplere alındı. Kan hücre çeşitleri otomatik kan sayım cihazı olan Beckman Coulter AU 2700 Plus (Beckman Coulter, Tokyo, Japonya) ile tespit edildi.

İstatistiksel analizler SPSS 20.0 (Statistical Package for Windows, Chicago, Illinois, USA) programı ile yapıldı. Verilerin normal dağııımını incelemek amacıyla Kolmogorov- Smirnov testi kullanıldı. Sayısal değişkenlerden normal dağılım sergileyenler (parametrik) ortalama, standart sapma olarak, normal dağılım sergilemeyenler (non-parametrik) ise ortanca, medyan değer olarak (beraberinde çeyrekler arası aralık ile) ve kategorik değişkenler yüzde olarak belirtildi. Sayısal değişkenler için Student-t testi veya Mann-Whitney U-testi, kategorik değişkenlerin analizi için ki-kare testi kullanıldı. Mitral anülüs kalsifikasyonu varlığını ön gördüren parametreler çok değişkenli lojistik regresyon analizi ile değerlendirildi.

\section{Sonuç}

Çalışma gruplarının bazal özellikleri ve laboratuar parametreleri Tablo 1'de gösterilmiştir. MAK (+) grubunda kontrol grubuna göre nötrofil sayısı daha yüksek $(p<0.001)$ ve lenfosit oranı daha düşük $(p<0.001)$ saptanmıştır. Diğer parametrelerde istatiksel olarak anlamlı fark izlenmemiştir.

Grupların elektrokardiyografik parametreleri Tablo 2'de gösterilmiştir. P Dalgası MAK (+) grubunda, kontrol grubuna göre anlamlı şekilde uzun izlenmiştir $(p<0.001)$. Düzeltilmiş QT intervali MAK $(+)$ grubunda, kontrol grubuna göre anlamlı olarak uzun izlenmiştir $(p<0.001)$. Tp-e intervali MAK (+) grubunda, kontrol grubuna göre anlamlı olarak uzun izlenmiştir $(p<0.001)$. Tp-e/ QT intervali ve Tp-e/ düzeltilmiş QT intervali oranı MAK (+) grubunda, kontrol grubuna göre anlamlı olarak uzun izlenmiştir $(p<0.001)$. Frontal QRS-T açısı MAK (+) grubunda anlamlı olarak fazla izlenmiştir $(p<0.001)$.

\section{Tartışma}

Bu çalışmada ana olarak MAK'ı hastalarda EKG değişiklikleri değerlendirilmiştir. MAK hastalarında atriyal iletimin göstergesi olan $\mathrm{P}$ dalgası süresinde anlamlı bozulma izlenmiştir. Ayrıca yeni aritmojenik idikatörler olan f(QRS - T) açısı ve Tp-e/QT de anlamlı bozulma izlenmiştir. Çalışmamız, EKG parametrelerini kullanarak MAK'In aritmojenik etkilerini inceleyen literatürdeki ilk çalışmadır. 


\begin{tabular}{|c|c|c|c|}
\hline Değişkenler & $\begin{array}{l}\text { MAK (+) } \\
(n=100)\end{array}$ & $\begin{array}{l}\text { Kontrol } \\
(n=100)\end{array}$ & p değer \\
\hline Yaş & $71.6 \pm 8.5$ & $69.5 \pm 9.9$ & 0.107 \\
\hline Erkek Cinsiyet, $\mathrm{n}$ & 44 & 49 & 0.478 \\
\hline Hipertansiyon, n & 32 & 42 & 0.143 \\
\hline Diabetes mellitus, $\mathrm{n}$ & 31 & 30 & 0.878 \\
\hline Sigara, $\mathrm{n}$ & 20 & 17 & 0.538 \\
\hline Koroner arter hastalığı öyküsü, n & 16 & 12 & 0.415 \\
\hline Hemoglobin, g/dl & $13.9 \pm 2.1$ & $13.6 \pm 1.8$ & 0.469 \\
\hline Platelet, $10^{9} / 1$ & $290 \pm 72.7$ & $269 \pm 48.8$ & 0.132 \\
\hline Beyaz Küre, 10/l & $7.8 \pm 2.7$ & $7.4 \pm 1.7$ & 0.157 \\
\hline Nötrofil, $10^{9} / l$ & $5.7 \pm 1.4$ & $4.3 \pm 1.2$ & $<0.001$ \\
\hline Lenfosit, 109// & $1.3 \pm 0.5$ & $2.3 \pm 0.7$ & $<0.001$ \\
\hline Monosit, $10^{8} / l$ & $0.6 \pm 0.2$ & $0.5 \pm 0.2$ & 0.379 \\
\hline Serum kreatinin, mg/dL & $1.1 \pm 0.3$ & $1.0 \pm 0.3$ & 0.663 \\
\hline Total kolesterol, mmol/l & $4.6 \pm 1.1$ & $4.6 \pm 0.6$ & 0.786 \\
\hline HDL kolesterol, mmol/l & $1.1 \pm 0.3$ & $1.2 \pm 0.2$ & 0.149 \\
\hline LDL kolesterol, mmol/l & $2.9 \pm 0.8$ & $2.7 \pm 0.5$ & 0.094 \\
\hline Trigliserit, mmol/l & $1.6 \pm 1.0$ & $1.6 \pm 0.7$ & 0.724 \\
\hline Sol ventrikül ejeksiyon fraksiyonu (\%) & $62.3 \pm 6.0$ & $62.4 \pm 5.8$ & 0.256 \\
\hline
\end{tabular}

HDL, yüksek yoğunluklu lipoprotein; LDL, yüksek yoğunluklu lipoprotein; MAK, mitral anüler kalsifikasyon.

Veriler ortalama \pm standart deviasyon veya yüzde olarak verilmiştir [n (\%)].

\begin{tabular}{|l|l|l|l|}
\hline Değişkenler & $\begin{array}{l}\text { MAK (+) } \\
(\mathbf{n = 1 0 0 )}\end{array}$ & $\begin{array}{l}\text { Kontrol } \\
(\mathbf{n = 1 0 0 )}\end{array}$ & p değeri \\
\hline Kalp Hızı (1 dakikada) & $79 \pm 18.5$ & $70.5 \pm 15.9$ & 0.351 \\
\hline QRS süresi (ms) & $99 \pm 15.9$ & $92 \pm 12.9$ & 0.278 \\
\hline PR intervali (ms) & $155 \pm 18.4$ & $158 \pm 19.3$ & 0.643 \\
\hline P Dalgası (ms) & $109 \pm 14.9$ & $89 \pm 11.3$ & $<0.001$ \\
\hline QT intervali (ms) & $384 \pm 20.5$ & $394 \pm 33.4$ & 0.198 \\
\hline QTc intervali (ms) & $481 \pm 26.4$ & $426 \pm 15.4$ & $<0.001$ \\
\hline Tp-e intervali, ms & $90 \pm 4.4$ & $81 \pm 5.1$ & $<\mathbf{0 . 0 0 1}$ \\
\hline Tp-e/QT oranı & $0.23 \pm 0.03$ & $0.20 \pm 0.02$ & $<\mathbf{0 . 0 0 1}$ \\
\hline Tp-e/QTc oranı & $0.19 \pm 0.02$ & $0.17 \pm 0.02)$ & $<\mathbf{0 . 0 0 1}$ \\
\hline f(QRS)-T ${ }^{\circ}$ ) & $69.2 \pm 36.5$ & $50.3 \pm 37.5$ & $<\mathbf{0 . 0 0 1}$ \\
\hline
\end{tabular}

QTC - düzeltilmiş QT intervali; MAK, mitral anüler kalsifikasyon; f(QRS-T; frontal QRS-T açıSı. 
Önceki çalışmalar, aterosklerotik kalp hastalığı için risk faktörleri olan olan yaş, diabetes mellitus, hipertansiyon ve obezite gibi risk faktörlerinin de MAK için de risk faktörleri olduğunu göstermiştir (18). Mitral anüler kalsifikasyonun, koroner arter hastalığı, karotid ve aortik ateroskleroz, kalp yetmezliği ve inme gibi kardiyovasküler hastalıklar ile yakın ilişkisi bulunmaktadır $(1,2)$. Kesin olarak bilinmeyen patofizyolojiyle birlikte, ateroskleroz riskinde artışa sebebiyet veren kalsiyum ve fosfor metabolizmasındaki dengesizlikler de MAK oluşumunda rol oynarlar (19). Deneysel olarak indüklenen sistemik arter aterosklerozu ile aort kapakçıklarının aortik tarafındaki ve posterior mitral yaprakçıkların ventrikül tarafındaki yağlı plakların birikmesinin ilişkisi gösterilmiştir (20). Bu nedenle, aterosklerotik lezyonlarınkine benzer patolojik bulgulara sahip olması ve ateroskleroz için risk faktörleri ile yakın iliş̧kisi nedeniyle MAK'ın aterosklerozun bir formu veya belirtisi olduğu düşünülmektedir (2). Birçok çaIışmada sistemik aterosklerozun kardiyak aritmilerle yakın ilişkisi olduğunu göstermektedir (21). Al-Mosawi ve arkadaşlarının bir çalışmasında QTc, Tp-e, Tp-e/ QTc ve koroner ateroskleroz arasında anlamlı ilişki saptanmıştır. Ateroskleroz ve MAK'ın yakın ilişkisi düşünüldüğünde, MAK ve aritmi patofizyolojisi arasında yakın ilişki bulunma potansiyeli vardır.

MAK sürecine bağlı olarak zaman içinde mitral kapakta dejenerasyon ve yetmezlik, buna bağlı olarak da sol atriyal genişleme ve remodelling gelişmektedir (22). Bu da çalışmamızda saptandığı gibi atriyal iletide gecikmeye ve $P$ dalgası uzamasına yol açmaktadır. Ayrıca MAK'ın bir inrakardiyak iletim sisteminde harabiyet ile sonuçlanan sklerodejeneratif bir süreç olduğu ve atriyal fibrilasyon riskinde artış ile ilişkili olduğu gösterilmiştir (22). Buna ek olarak MAK'lı hastalarda intraventriküler kalsiyum birikimi de artmıştır (23). Çaıışmamızda saptadığımız repolarizasyon parametrelerindeki bozulmanın bu fenomenle ilişkili olma potansiyeli bulunmaktadır. Başka bir çalışmada da MAK'ın kalp hızı değişkenliği ve dolayısı ile parasempatik ve sempatik inervasyonda bozulma ile ilişkili olduğu bulunmuştur (24). Bu dengedeki bozulmanın MAK bulunan hastalarda artmış kardiyovasküler mortalitenin sebeplerinden biri olma potansiyeli vardır (25).

Ventriküler depolarizasyonun elektriksel yönü ile repolarizasyon arasındaki açı olan f(QRS-T) açısı, miyokardiyal depolarizasyon ve repolarizasyon heterojenliğinin yeni bir göstergesidir (11, 17). Çalışmalar f(QRS-T) açısının daha sağlam ve tekrarlanabilir olduğunu ve diğer geleneksel elektrokardiyografik miyokardiyal repolarizasyon parametrelerine göre gürültü ve tanım problemlerinden daha az etkilendiği gösterilmiştir (17). Normal olarak, miyokardiyal depo- larizasyon ekseni ve repolarizasyon ekseninin yönleri benzer bir yönelime sahiptir. Yani, f(QRS-T) açısı genellikle dar bir açı $\left(<45-50{ }^{\circ}\right)$ olma eğilimindedir (26). Daha geniş bir f(QRS-T) açısı ventriküler depolarizasyon fazı ve repolarizasyon fazı arasındaki uyumsuzluğu gösterir. Akut ST-segment yükselmesi miyokard enfarktüslü hastalarda bir f(QRS-T) açıSı artışı artmış mortalite ile ilişkili bulunmuştur (13). Çalışmamızda da f(QRS-T) açısı normal sayılan değerlerin oldukça üstünde saptanmıştır.

QT dispersiyonu, uzun süre repolarizasyonun artmış dispersiyonunun bir işareti olarak temsil edilmiştir, ancak günümüzde önemini yitirmeye başlamıştır (8). Günümüzde, Tp-e aralığı ve Tp-e/QT oranı, ventriküler repolarizasyonun ve artmış dispersiyonunun ana göstergeleri olarak değerlendirilmeye başlanmıştır (10). Son zamanlarda yapılan çalışmalarda, Tp-e/QT oranının, QT dispersiyonu, QTc dispersiyonu ve Tp-e aralıklarından daha ventriküler repolarizasyon dağılımının daha doğru bir ölçümü olduğu ve kalp hızında varyasyonlardan bağımsız olduğu bulunmuştur. Ayrıca artmış Tp-e/QT oranı artmış aritmojenik olaylarla ilişkilidir. Çalışmamızda da MAK'।ı hastalarda Tp-e/ QT oranı belirgin şekilde artmış bulunmuştur.

Bu çalışmada, ilk defa büyük ölçekli bir kohortta MAK'ın EKG üzerindeki etkileri değerlendirilmiştir ve literatürde ilk kez MAK'ın kalbin repolarizasyon parametreleri üzerinde negatif etkileri olduğu saptanmıştır. Çalışmamızın sonuçları göz önüne alındığında MAK'। olan hastalarda aritmik riskin artma potansiyeli olduğu göz önünde bulundurulmalıdır. Bu yüksek riskli popülasyonda, daha yakın takipler düzenlenebilir. Ancak bu hipotezi açıklığa kavuşturmak için çok merkezli, geniş ölçekli, randomize ve prospektif çalışmalar gereklidir.

\section{Çalışmanın Kısıtlılıkları}

Çalışmamızın bazı kısıtıııkları bunmaktadır. Çalışma tasarımı nedeniyle MAK'ın prognostik değerini gösteren verilerimiz mevcut değildir. Bunun yanında, istatistiksel analiz için anlık bakılan tek bir EKG kullanıldı. Bu nedenle EKG'nin zaman içerisindeki değişimi incelenememiştir.

\section{Finansman}

Bu araştırma, kamu, ticari veya kar amacı gütmeyen sektörlerdeki herhangi bir finansman kuruluşundan özel bir bağış almadı.

\section{Çıkar Çatışması}

Yazarın bu makaleyi hazırlarken çıkar çatışması bildirmemiştir. 


\section{Kaynaklar}

1. Adler Y, Herz I, Vaturi M, Fusman R, Shohat-Zabarski R, Fink $\mathrm{N}$, et al. Mitral annular calcium detected by transthoracic echocardiography is a marker for high prevalence and severity of coronary artery disease in patients undergoing coronary angiography. Am J Cardiol. 1998;82(10):1183-6.

2. Adler Y, Koren A, Fink N, Tanne D, Fusman R, Assali A, et al. Association between mitral annulus calcification and carotid atherosclerotic disease. Stroke. 1998;29(9):1833-7.

3. Fox CS, Vasan RS, Parise H, Levy D, O'Donnell CJ, D'Agostino RB, et al. Mitral Annular Calcification Predicts Cardiovascular Morbidity and Mortality. Circulation. 2003;107(11):1492.

4. Allison MA, Cheung P, Criqui MH, Langer RD, Wright CM. Mitral and aortic annular calcification are highly associated with systemic calcified atherosclerosis. Circulation. 2006;113(6):861-6.

5. Aronow WS, Schwartz KS, Koenigsberg M. Correlation of serum lipids, calcium and phosphorus, diabetes mellitus, aortic valve stenosis and history of systemic hypertension with presence or absence of mitral anular calcium in persons older than 62 years in a long-term health care facility. Am J Cardiol. 1987;59(4):381-2.

6. Afshar M, Luk K, Do R, Dufresne L, Owens DS, Harris TB, et al. Association of Triglyceride-Related Genetic Variants With Mitral Annular Calcification. J Am Coll Cardiol. 2017;69(24):2941-8.

7. Algra A, Tijssen JG, Roelandt JR, Pool J, Lubsen J. QTc prolongation measured by standard 12-lead electrocardiography is an independent risk factor for sudden death due to cardiac arrest. Circulation. 1991;83(6):1888-94.

8. Kors JA, Ritsema van Eck HJ, van Herpen G. The meaning of the Tp-Te interval and its diagnostic value. Journal of electrocardiology. 2008;41(6):575-80.

9. Erikssen G, Liestol K, Gullestad L, Haugaa KH, Bendz B, Amlie JP. The terminal part of the QT interval (T peak to T end): a predictor of mortality after acute myocardial infarction. Annals of noninvasive electrocardiology : the official journal of the International Society for Holter and Noninvasive Electrocardiology, Inc. 2012;17(2):85-94.

10. Gupta P, Patel C, Patel H, Narayanaswamy S, Malhotra B, Green JT, et al. T(p-e)/QT ratio as an index of arrhythmogenesis. Journal of electrocardiology. 2008;41(6):567-74.

11. Macfarlane PW. The frontal plane QRS-T angle. EP Europace. 2012;14(6):773-5.

12. Andrew O, Trevor F, A. HC, G. TL. QRS-T Angle: A Review. Annals of Noninvasive Electrocardiology. 2014;19(6):534-42.

13. Raposeiras-Roubin S, Virgos-Lamela A, Bouzas-Cruz N, Lopez-Lopez A, Castineira-Busto M, Fernandez-Garda R, et al. Usefulness of the QRS-T angle to improve long-term risk stratification of patients with acute myocardial infarction and depressed left ventricular ejection fraction. Am J Cardiol. 2014;113(8):1312-9.

14. Kurtoðlu E, Aktürk E, Korkmaz $\mathrm{H}$, Atap $\mathrm{H}$, Pekdemir H. Impaired heart rate variability in patients with mitral annular calcification: an observational study. The Anatolian Journal of Cardiology. 2013;13(7):668-74.

15. Potpara TS, Vasiljevic ZM, Vujisic-Tesic BD, Marinkovic JM, Polovina MM, Stepanovic JM, et al. Mitral annular calcification predicts cardiovascular morbidity and mortality in middle-aged patients with atrial fibrillation: the Belgrade Atrial Fibrillation Study. Chest. 2011;140(4):902-10.

16. Hevia JC, Antzelevitch C, Bárzaga FT, Sánchez MD, Balea FD, Molina RZ, et al. Tpeak-Tend and Tpeak-Tend Dispersion as Risk Factors for Ventricular Tachycardia/ Ventricular Fibrillation in Patients With the Brugada Syndrome. Journal of the American College of Cardiology. 2006;47(9):1828-34.

17. Zhang Z-m, Rautaharju PM, Prineas RJ, Tereshchenko L, Soliman EZ. Electrocardiographic QRS-T angle and the risk of incident silent myocardial infarction in the Atherosclerosis Risk in Communities study. Journal of electrocardiology.
2017;50(5):661-6.

18. Kanjanauthai S, Nasir K, Katz R, Rivera JJ, Takasu J, Blumenthal RS, et al. Relationships of mitral annular calcification to cardiovascular risk factors: the Multi-Ethnic Study of Atherosclerosis (MESA). Atherosclerosis. 2010;213(2):558-62.

19. Fox CS, Larson MG, Vasan RS, Guo CY, Parise H, Levy D, et al. Cross-sectional association of kidney function with valvular and annular calcification: the Framingham heart study. J Am Soc Nephrol. 2006;17(2):521-7.

20. Thubrikar MJ, Deck JD, Aouad J, Chen JM. Intramural stress as a causative factor in atherosclerotic lesions of the aortic valve. Atherosclerosis. 1985;55(3):299-311.

21. Plotnick GD, Fisher ML, Becker LC. Ventricular arrhythmias in patients with rest angina: correlation with ST segment changes and extent of coronary atherosclerosis. American heart journal. 1983;105(1):32-6.

22. Fulkerson PK, Beaver BM, Auseon JC, Graber HL. Calcification of the mitral annulus: etiology, clinical associations, complications and therapy. The American journal of medicine. 1979;66(6):967-77.

23. Wang AY, Ho SS, Wang M, Liu EK, Ho S, Li PK, et al. Cardiac valvular calcification as a marker of atherosclerosis and arterial calcification in end-stage renal disease. Archives of internal medicine. 2005;165(3):327-32.

24. Kurtoglu E, Akturk E, Korkmaz H, Atas H, Cuglan B, Pekdemir $\mathrm{H}$. Impaired heart rate variability in patients with mitral annular calcification: an observational study. Anadolu kardiyoloji dergisi : AKD = the Anatolian journal of cardiology. 2013;13(7):668-74.

25 . Heart rate variability: standards of measurement, physiological interpretation and clinical use. Task Force of the European Society of Cardiology and the North American Society of Pacing and Electrophysiology. Circulation. 1996;93(5):1043-65.

26. Gungor M, Celik M, Yalcinkaya E, Polat AT, Yuksel UC, Yildirim $\mathrm{E}$, et al. The Value of Frontal Planar QRS-T Angle in Patients without Angiographically Apparent Atherosclerosis. Medical principles and practice : international journal of the Kuwait University, Health Science Centre. 2017;26(2):125-31. 